\title{
Effectiveness of Context on Translation in Literary Works
}

\author{
Lin Lin \\ Foreign Language College \\ Huanghe Science and Technology College \\ Zhengzhou, China
}

\begin{abstract}
Context has very close connection with translation especially with literary translation. In literary works, context has an important function restricting translation process, and in turn translation, to a large degree, depends on context. Context is indispensable for translators to correctly understand the original text and to achieve functional equivalence in translation. This paper, from the perspective of systemic-functional linguistics, holds that context is the key to comprehend the original text, and that only when we convey the true communicative intentions of the original work via context, can it be possible to guarantee the maximum success of translation in literary works.
\end{abstract}

Keywords-context; translation; effectiveness; literary works

\section{INTRODUCTION}

Literary work is the product of the communication between the writer and reader. Context plays a very important part in both the writer's writing process and the reader's understanding process. More significantly, as the communicative bridge between the writer and the reader, the translation must give high value on the role of context. The meaning of any word, sentence, even paragraph may be floating, and can get fixed only when they are occurring in a certain context. Therefore, context is indispensable for the correct understanding of the original text, and a key to achieve functional equivalence in translation. This paper purports to explain context from the perspective of systemicfunctional linguistics, and try to analyze the effectiveness of different forms of context on translation in literary works.

\section{CONTEXT}

For the theory of context, the three prominent representatives of London School, Malinowsky, Firth and Halliday have successively contributed so much to its proposition and development. The three scholars all laid stresses on the functions of language and attached great importance to the context of situation and the system aspect of language. Thus, London School is also known as systemic linguistics and functional linguistics.

The notion of context was first proposed in 1932 by Bronislaw Kaspar Malinowsky, the famous British anthropologist. He distinguished two kinds of context: context of situation and context of culture, and held that context is the only factor to decide meaning. Then John Rupert Firth, the British linguist and founder of London School, inherited and developed this notion, holding that meaning is the function of language elements in context. He defined the context of situation as including the entire cultural setting of speech and the personal history of the participants rather than as simply the context of human activity going on at the moment. Firth accepted the term 'context of situation' and stipulated the following categories:

- the relevant features of the participants: persons, personalities

the verbal action of the participants

the non-verbal action of the participants

- the relevant topics, including objects, events, and non-linguistic, non-human events

- the effects of the verbal action

Firth's basic theory was later inherited and developed by the well-known modern linguist, M.A.K. Halliday. In his register theory, he believes that situational context has three comprising factors.

field of discourse --- the environment in which speech activity occurs

tenor of discourse --- the relationships among participants

mode of discourse --- the channel or media for speech communication

To sum up, context consists of the knowledge shared by the speaker and the hearer. It includes the knowledge of the language they use, the specific knowledge about the situation in which communication is taking place, and the general knowledge about the world. Context can be generally classified into the following three types:

- linguistic context, also known text context, or verbal context, is context in its narrow sense, containing purely linguistic factors.

- situational context, the actual situation when speech activity occurs, or communicative situation. 
- cultural context, the context in its broad sense, refers to the entire social culture of a certain speech community.

The study of context has great significance for translation especially for literary translation. Next we will follow the above division and go on to discuss the three context's effectiveness on translation in literary works.

\section{EFFECTIVENESS ON TRANSLATION}

\section{A. Linguistic Context}

According to the classification, we know linguistic context refers to the linguistic environment in which a linguistic unit occurs, that is, the preceding and following words, sentences, or even paragraphs in a text. Just as British linguist Firth said, "Each word when used in a new context is a new word." A word, if viewed in isolation, is only a symbol; it acquires its meaning only when it appears in specific context. Meaning is not something that exists in words, but something that exists in the relations between words and the environment where they occur. So in order to assign meaning to a word or a sentence, one has to study the context in which it is used. Take some lines in literary texts for example,

1)The doctor is performing an operation on a patient for appendicitis.

\section{2)These speculators carry on black market operations.}

3)The military operations embody the tactical use of atomic weapons.

\section{4)Our class learns the law of four operations.}

In this case, the same word "operation" has different interpretation owing to different linguistic context. If we simply translate the word "operation," regardless of the context in which it occurs, as “手术” in all the sentences listed above, the translation would be absolutely wrong.

As for the English word "green", we could blurt out at first glance that its Chinese equivalent is “绿”. However, its meaning are not all necessarily “绿”. Hence, we should pay much attention to its linguistic context in comprehending and translating it, or we will possibly make mistakes in translation. For instance:

\section{a green Christmas \\ a girl green from school \\ a green old age \\ green with envy \\ in green tree}

\section{keep the memory green}

In this example, word "green" can be seen as a meaning core, and the meanings derivate from the collocations with its neighboring words can form a radiation of meaning. If we neglect the context and translate "green" as “绿” in all the phrases and sentences, we will be definitely laughed at by others.

We could see from the above examples that context helps to reach the correct understanding of the original work. Words tend to be polysemous. They have more than one meaning. The question of which meaning should be taken could be settled only when they are put in specific context. Linguistic context contributes too much to grasp the proper meaning and furnish the exact translation.

\section{B. Situational Context}

According to the classification, situational context refers to the actual communicative situation when speech activity occurs, including objective factors and subjective factors.

1) objective factors.

It is agreed that objective factors mainly include factors like time, place, occasion, mode etc.

a) time

Time, as a context factor, refers to the time when the speech occurs. The same utterance spoken in different time always has different meaning. For example:

A: When will Professor Li visit our university?

B: He will visit our university next May.

"next May" has two interpretations. If it is any time after May $1^{\text {st }}$ when the utterance is being spoken, the phrase "next May" refers to May of next year. However, if it is any time in the period between Jan $1^{\text {st }}$ and April $30^{\text {th }}$, it means May of this year.

\section{b) place}

Place, as a context factor, refers to the place where speech activity happens. By the same token, meaning of utterances is closely related to the specific place. For example:

\section{It's time to go aboard.}

If it is in the railway station at the moment of speaking, it ought to be translated as “该上车了”, whereas if it is an airport, the translation should be “该上飞机了”.

\section{c) occasion}

Consideration of occasion on which speech communication is taking place helps translators comprehend the situational meaning and context meaning of the original. In speech communication, one person may employ different expressions in accordance to the varying occasions, and thus we should choose the most appropriate equivalent in the translation. This could be exemplified by the following excerpt taken from A Dream of Red Mansions, translated by Yang Yixian and Dai Naidie.

$$
\text { with tear she told him, "Simple farmers". }
$$

with tears too he replied, "Your Subject, poor and obscure. Little dreamed that our flock of common pigeons and crows would even be blessed with a phoenix. Thanks to the Imperial favor and the virtue of our ancestors, your 
Noble Highness embodies the finest essences of nature and the accumulated merit of our forbears---such fortune has attended my wife and my self. Your Noble Highness must not grieve your precious heart in concern for your aging parents. We beg you to take better care of your own health..."

We could see that the excerpt is faithfully translated from Chinese into English. In A Dream of Red Mansions, the character Jia Zheng, as a loyal guardian of feudalism, knows very well the rigid hierarchy in feudal society, so on the occasion described in the excerpt, he, even in front of his daughter, Princess Yuan, calls himself and his wife “臣”, “䴓 群鸦属”, “政夫妇”, which are correspondingly translated as "Your Subject", "Our flock of common pigeons and crows", "my wife and my self". In this paragraph, Jia zheng also addresses her daughter by words “贵人”, “贵妃”, “凤”, for which the translator give the true and exact translation as "Your Noble Highness" and "phoenix".

\section{d) mode}

This context factor refers to the manner or mode of speech communication, or the media of language activity. As language's modes of expression are mainly two kinds: colloquial and written, the modes of speech have also two kinds like that. They are clearly different from each other in that colloquial style may be spontaneous or not, while the written style is used for reading and oral expression for readers. Hence this difference must be fully realized and reflected when the original is being translated into the target language. We exemplify it with two versions of the short dialogue excerpted from play Glass Zoo by Tennessee William.

\section{LAURA(rising): Mother, let me clear the table.}

AMANDA: No, dear, you go in front and study your typewriter chart. Or practice your shorthand a little.

That is a dialogue between mother and daughter in the play, and obviously version B is better, for it employs the colloquial style, which is characteristic of play, so as to be more suitable for acting and appreciation. This example shows that translators should pay more attention to the media relevant to language, namely, the mode that source language is used to express and convey meaning.

\section{2) subjective factors}

Subjective factors refers to those context factors closely related to the participants of speech activity, such as participants' identity, education, social position, character, and mood while speaking.

\section{a) identity}

The meaning of the same word varies when applying to different identities of communicators. We should choose corresponding translation suitable for the identities of characters. There is a simple example:

\section{Good morning, Doctor Li!}

In this utterance, “doctor" has two interpretations:

\section{(1)person licensed to practice medicine}

\section{(2)person who has been awarded a doctorate}

We can depend on the identity of the addressee in discourse situation to decide which interpretation to be taken. If the identity of the addressee is the first one, the appropriate target language should be “早上好, 李医生” ; if the second one is taken, then the translation should be “早上好, 李博 士”.

Another example is an excerpt from play The School for Scandal by Richard Brinsley Sheridan:

That's in as fine a train as your ladyship could wish. In the common course of things, I think it must reach Mrs. Clackitt's ears within four and twenty hours; and then, you know, the business is as good as done.

The above lines are spoken by Snake to Lady Sneerwell. In the original, Snake has already addressed Lady Sneerwell by "your ladyship", so it is appropriate to translate "you" in “you know” as “夫人”, the honorific title.

If we adopt a literal translation approach and translate it simply as “你”, the relationship between the two characters will not be able to be fully embodied. In contrast, according to the context factor concerning the communicator's identity, the liberal translation “夫人” instead will show vividly the identities of characters as well as their relationship.

\section{b) education}

Due to differences in the degree of education, people speak in quite different manners. The well-educated people use polite and elegant wordings; while the less-educated tend to be ill-mannered, using uncivilized and vulgar diction in their speech. These language differences should also be reflected in good translation. This will be exemplified by the following three lines, taken from play My Fair Lady, translated by Yang Xianyi.

\section{(1)Nah then, Freddy: look why's gowin, deah.}

(2)The shadow depression in the west of these islands is to move slowly in an easterly direction. There are no indications of any great change in the barometric situation.

(3)How do you do. Professor Higgins. Are you quite well...But of course you are: you are never ill. So glad to see you again. Colonel Pickering. Quite chilly this morning, isn't it?

The flower girl is the heroin in Bernard Shaw's play My Fair Lady. She did not receive any education, vulgar in language and with strong provincial accent. Mr. Higgins put her into a language training to make her ladylike and wellmannered, with standard pronunciation, elegant speech, and proper behavior. The above example marvelously displays her progress in the training. Line (1) is her utterance before language training, sounds vulgar and not standard. The translation transplanted this language characteristic by the square. Line (2) is what she said after a short period of training. Obviously she has not yet mastered idiomatic English, trying to use genteel written language in daily conversation, yet ill-suited to the context. Translators use corresponding Chinese written language to transmit the 
language effect in the original to the target language successfully. Line (3) is what the flower girl says after six months of training, speech style being refined and decent. Mr. Yang Xianyi paid much attention to the progress the heroin is gaining in translating this line. All the three translations faithfully recur her language characteristic at different phases of training.

\section{c) social position}

Under situational context, the social position of communicators in discourse sometimes has to be considered in order to convey all the situational and context implicature in the original to the target language. The following example is another excerpt from play My fair Lady, showing the importance of this of this situational factor in translation.

\section{The Flower Girl: ... Will ye-oo py me fthem?}

The Daughter: Do nothing of the sort, mother. The idea.

The setting of this discourse is: a mother and her daughter, both well-heeled, are waiting a taxi in the rain. The daughter brushes up against the flower girl and drops her flower off on the muddy road in a hurry when she runs to call a taxi, which turns the flower girl to be very angry, asking her mother to pay for it. That proud and high-fed daughter looks down upon her, the dirty, vulgar and low flower girl. In that situation, she said that utterance to her mother. Here to exactly convey the situational meaning of "The idea" is very difficult, for you could hardly find its corresponding Chinese translation even though looking through all the dictionaries.

The translation “她想得倒美” conveyed exactly and vividly the implicature under situational context, even unparalleled compared with any other translation. "The idea" was endowed with special implicature and rich emotion. It is the consideration of social positions of characters that this translation successfully retained and reproduced the language color and emotion factors in the original. This vivid translation enables its readers to be able to perceive at once the proud daughter's scorn and superiority over the lowdown flower girl.

So in translating similar texts, translators should consider the situational role and social positions of characters in order to achieve functional equivalence in translation.

\section{d) character}

Speech is the important means of revealing the inside world of person's consciousness. Different characters of people also have certain influence on their speech style. In order to depict character, translators should pay special attention to the individuality of character language and try to recur the likeness of a character. For example:

... said Mr. Micawber, in another burst of confidence, "that you might lose yourself --- I shall be happy to call this evening and install you in the knowledge of the nearest ways."

This is an excerpt from David Copperfield, in which, Mr. Micawber speaks with a sort of gentleman's tune-pattern, and likes to talk in a roundabout way. The above translation did not display this personal characteristic of his, thus in essence distorted the image of Mr. Micawber. The revised translation is as follows:

\section{e) mood}

The task of translators is to convey the communicative intentions of speakers in discourse. Some translations is correct seen from the angle of lexical or grammatical meaning, yet from the angle functional equivalence, the standard proposed by famous translation Eugine Nida, still need to be polished and refined. As a context factor, mood of communicators at the moment of speaking also has effect on their speech and then on translation. We should convey the true communicative intentions of the original with reference to it to give proper translation. For example:

"Wicked man and cruel boy!" I said. "You are like a murderer---You are like a slave-driver---You are like the Roman emperors!"

These are lines spoken by Jane Eyre when she was quarreling with her cousin. Obviously this translation did not tally with the context implicature, for it did not express the state of mind of speaker incisively and vividly. Pondering over the original text, we could perceive that little Jane Eyre was very angry at that time, so her speech could not be so heartsease. The revised version is as follows:

We could easily see that this translation fully conveyed the context meaning of the original so as to achieve contextual and functional equivalence.

To sum up, translation by means of situational context will unavoidably involve the above discussed factors, and neglect of them inevitably results in inaccurate translation. So in the process of translation, we should more concerned ourselves with the situational context in which communication is taken place, and improve our ability of analyzing context to contribute ideal translation.

\section{Cultural Context}

Cultural context is the context in the broad sense. It refers to the social normal and customs as the specific culture of a speech community. Language is the vehicle of culture, culture is the soil of language, while translation is the bridge for cross-cultural communication. Translation is not simply the conversion of language and words at the superficial level, but rather the transplantation of one culture into another. Translation involves two culture more than just two languages. So cultural differences unavoidably have great influence on translation. Therefore, in the process of translation, only when we attach importance to the cultural context in which the original text occurs, can the language barrier be overcome in intercultural communication. Cultural context generally includes such main aspects as historical and cultural background, natural environment, values, social custom and habits, and religious belief and allusions etc. 


\section{1) historical and cultural background}

As an important context factor, different historical and cultural background always influences comprehension and expression of some utterances. For example:

The political situation is as if the sword of Damocles hung over the government.

For those people who are not familiar with that story in ancient Greek culture, which exerts enormous and farreaching influences upon European culture, they could not understand what "the sword of Damocles" means. The legend is that, in $4^{\text {th }} \mathrm{BC}$, the king of Syrakus, Dionysios, has a minister names Damocles, who admires the king very much, thinking the king is the happiest person in the world. Dionysios orders him to sit in his throne in a party, with a sword hanging over his head, to make him realize that even the king is in face of great danger at any time. That's the origin of the phrase, meaning the impendent danger. Hence, in the historical and cultural context of Europe, the sight of the sword of Damocles is associated with the idea of the dangerous situation. In contrast, in the historical and cultural context of China, people do not have this image, what can be thought is only a sword. The literal translation obviously could not convey adequate context meaning to achieve functional equivalence between the two languages. So we could adopt the method of 'image retained plus note' to translate it into:

\section{2) natural environment}

Ecological environment, as a regional culture, also has certain influence on the referential meaning of words. Differences of natural environment between two countries should also be noticed in translation. The translation of Shakespeare's Sonnet XV III shows the importance of this aspect.

\section{Shall I compare thee to a summer's day?}

Thou art more lovely and more temperate:

Rough winds do shake the darling buds of May,

\section{And summer's lease hath all to short a date:}

Here comes an improper translation caused by different geographical culture. Because the summer in Britain is mild and lovely, the comparison of "you" to "summer" is very proper. If the summer in the target language country, such as in China, is not as lovely as in Britain, and spring is the best season, then “春天” is more proper than “夏天” in translating the word "summer".

\section{3) values}

Different values have been formed on a long way for different nations, so even many seemingly same objects have quite opposite connotations in different countries as a result of differences in values. For example, let us read the following stanza by Robert Burns:

John, Anderson, my Jo, John,

When we were first acquaint,

Your locks were like the raven,
Your bonnie brow was brent.

The Chinese version by Liang Yuchun(梁遇春)[3]:

\section{John, Anderson, 我的爱人, John}

The poet compared his lover's locks with that of the raven, which has no derogatory connotation. But to a Chinese, the raven is unwelcome, unpleasant, and is usually associated with derogatory sense, such as in the expression “乌鸦嘴” and “天下乌鸦一般黑”. The Chinese version retains the metaphor, but runs counter to the aesthetic standards of Chinese readers; therefore, the original meaning of the poem may not be perfectly represented. The revised translation is as follows:

\section{4) social custom and habits}

Differences in social custom and habits between two nations have great effectiveness on translation. For example, in Britain, the weather changes a lot, and so people have a special feeling for weather. "Lovely day, isn't it?" becomes the most convenient and safe greeting. In China, the problem of daily bread has been the subject people have been concerned with. When one comes across an acquaintance in the street, he is most likely to say, “你吃饭了吗?” This is just a way of greeting, speakers do not expect an answer to this question from the hearer. While in western countries, if you asked, "Have you had your meal?" The first psychological reaction of foreigners will be "Yes. I have." "No. I haven't." or "Do you mean to invite me to dinner?" So if we meet with the similar situation in literary works, we couldn't translate the Chinese utterance “你吃饭了吗?” directly into English "Have you had your meal?", instead that's OK to translate it into "How do you do!" or "Hello". Therefore, in translation, we should infer the communicative intentions of speaker between lines according to cultural context, and then put it into appropriate expressions in accordance with the habits of readers.

\section{5) religious belief and allusions}

There exist great discrepancies in religious belief and allusion between western and eastern culture. In western countries, people mostly embrace Christianism, holding that God creates everything. There are many words related to religion such "Bible", "baptize", "cathedral", "god" etc. Whereas Chinese are inclined to believe in Buddhism and Taoism. They have many religious words like “玉帝”, “观 音”, “菩萨”, “佛主”, “慈悲为怀” etc. This discrepancy should be paid much attention in translation. Please look at this example,

Being a teacher is being present at the creation, when the clay beings begin to breathe.

Christianism believes that God created people, and people come from clay. So in English, the word "creation" refers to God, and "clay" refers to people created by God. After understanding the religious connotation of these two words, this sentence can be translated into

Without the background knowledge of western religion, we will have a difficult time in comprehending this sentence, let alone to give the correct translation. 
In Chinese culture, historical allusions are rich and colorful, such as “盘古开天”, “牛郎织女”, “项庄舞剑”, “卧 薪尝胆”. In western culture, the majority of allusions are originated from Bible, Roman and Greek myths. This difference affects translation to some degree. For example,

\section{You are just a doubting Thomas.}

In this sentence, the source of "doubting Thomas" is one story in Bible. People familiar with western culture would know that Thomas is one of the 12 disciples of Jesus Christ, and he is born to be suspicious, never believing others. Later the phrase "doubting Thomas" is used to describe doubtful people. For this example, if we translate it directly into “你 是一个多疑的托马斯”, the Chinese readers who know little about western allusions, would not know who is Thomas, and what sort of man he is. So we should translate it according to meaning, “你这个人真多疑”, to convey all the context meaning it contains to the Chinese readers.

Different religious belief and historical allusions in western and eastern culture are permeated in their own language expressions. Only when we have a profound understanding of the discrepancies between western and eastern culture, and comprehend the cultural connotation in language, can mistakes in translation be avoided so as to make translation really plays a role for cultural communication.

From what was discussed above, it is better for us to conclude that cultural context has great effectiveness on translation, and translation is more closely related to cultural factors in language. Without the cultural knowledge, it is difficult to translate the original into target language accurately. Only by systematic and concrete contrast between two cultures, can it be possible to recognize cultural characteristics and achieve relative translation equivalence.

\section{CONCLUSION}

We have illustrated context's effectiveness on translation in literary works from three aspects: linguistic context, situational context, and cultural context. In actual process of translation, it is often the case that more than one type of context are interwoven together and have a mutual role in speech. In order to comprehend utterance meaning accurately and express the communicative intention properly, context has to be utilized and taken into consideration to convey context implicature of the original as much as possible. Context is the most important factor in all the translations, of greater importance than any rules, any theories and any basic meaning of lexicon.[1] So all in all, context and translation are closely related to each other. Context has a restrictive function to translation, and translation depends on context. Hence, in engaging in translation activity, we should fully consider all kinds of context factors, correctly comprehend and convey complete information of the original, striving to achieve contextual and functional equivalence.

\section{REFERENCES}

[1] Haiqing Jiang, "Context and Translation", Foreign Language Study, 2004(5): pp.56.

[2] Jin Zhang, The Principles of Literary Translation. Kaifeng: Henan University Press, 1998.

[3] Jinfu Liu, "The Application of Criticism in Translation Teaching", in Chinan Translation, 1996(5): pp.27.

[4] Leo Hickey, The Pragmatics of Translation. Shanghai: Shanghai Foreign Language Education Press, 2001.

[5] Qinghua Feng, Practical Translation Coursebook. Shanghai: Shanghai Foreign Language Education Press, 2003.

[6] Xiaohong Luan, "Cultural Differences and Language Translation", in Jornal of Anhui Agricultural University (Social Science Edition), 2001.

[7] Yunqiang Cen, An Introduction to Linguistics. Beijing: China People's University Press, 2003.

[8] Zhuanglin Hu, Course of Linguistics. Beijing: Bejing University Press, 2001.

[9] Zongyan Wang, Traits and Trend of Modern Linguistics. Shanghai: Shanghai Foreign Language Education Press, 1997.

[10] Zhuang Yuguang, Hu Shi. Architectural Ornament in Ancient China • Sculpture [M], Jiangsu Fine Arts Publishing House in Nanjing, in 2007

[11] Ma Shichang, Ding Mingyi. Introduction to Archaeology of Chinese Buddhist Grottoes [M], Beijing: Cultural Relics Press, 2007

[12] Tang Yongtong. Buddhism History of Han, Wei, Jin, Southern and Northern Dynasties [M], Shanghai: Shanghai Bookstore Publishing House, 1991

[13] Cultural Relics Work Team in Bureau of Culture in Henan Province, Gongxian Cave Temple [M], Beijing: Cultural Relics Publishing House, 1963

[14] Jing Sanlin. Art History of Chinese Grottoes Sculpture [M], Beijing: People's Fine Arts Publishing House, 1988:149

[15] Zhang Weiqing, Gao Yiqing. The History of Chinese CultureVolume Four [M], Shandong: Shandong People's Publishing House, Ed.1, Feb. 2002 